\title{
Systematic Parasitology
}

\section{A new species of Schoutedenichia Jadin \& Vercammen-Grandjean, 1954 from Madagascar and a re-description of S. dutoiti (Radford, 1948) from South Africa (Acariformes: Trombiculidae) \\ --Manuscript Draft--}

Manuscript Number:

Full Title:

Article Type:

Keywords:

Funding Information:

Abstract:

Corresponding Author:
SYPA-D-19-00033R2

A new species of Schoutedenichia Jadin \& Vercammen-Grandjean, 1954 from Madagascar and a re-description of S. dutoiti (Radford, 1948) from South Africa (Acariformes: Trombiculidae)

Original Research Paper

chiggers; Taxonomy; Microcebus host; rodent hosts; new species; ectoparasites; Madagascar; South Africa

\begin{tabular}{|l|l|}
$\begin{array}{l}\text { Russian Foundation for Basic Research } \\
\text { (16-04-00145-a) }\end{array}$ & Dr. Alexandr A. Steko \\
$\begin{array}{l}\text { Lewis and Clark Fund of the American } \\
\text { Philosophical Society }\end{array}$ & Sharon E. Kessler \\
$\begin{array}{l}\text { NSF Dissertation Improvement Grant } \\
\text { (0961779) }\end{array}$ & Sharon E. Kessler \\
the Animal Behaviour Society & Sharon E. Kessler \\
\hline $\begin{array}{l}\text { Sigma Xi } \\
\text { (G2009101504) }\end{array}$ & Sharon E. Kessler \\
\hline $\begin{array}{l}\text { Sigma Xi (Arizona State University } \\
\text { chapter) }\end{array}$ & Sharon E. Kessler \\
\hline $\begin{array}{l}\text { American Society of Primatologists } \\
\text { Arizona State University School of Human } \\
\text { Evolution and Social Change }\end{array}$ & Sharon E. Kessler \\
\hline $\begin{array}{l}\text { Arizona State University Graduate and } \\
\text { Professional Student Association }\end{array}$ & Sharon E. Kessler \\
\hline Universiteit Stellenbosch & Sonja Matthee \\
\hline $\begin{array}{l}\text { National Research Foundation (South } \\
\text { Africa) }\end{array}$ & Sonja Matthee \\
\hline $\begin{array}{l}\text { Stiftung Tierärztliche Hochschule } \\
\text { Hannover }\end{array}$ & $\begin{array}{l}\text { Alida F. Hasiniaina } \\
\text { Ute Radespiel }\end{array}$ \\
\hline EEO Scholar Award & Elke Zimmermann \\
\hline Sharon E. Kessler
\end{tabular}

A new chigger mite species, Schoutedenichia microcebi $\mathrm{n}$. $\mathrm{sp}$. is described from the grey mouse lemur Microcebus murinus (J.F. Miller) from Madagascar. The new species is closely related to $S$. dutoiti (Radford, 1948), a species described from a single specimen collected on a rodent in South Africa. Examination of the holotype and new material on S. dutoiti from South Africa enabled us to re-describe this species and provide new data on its hosts and geographical distribution.

Alexandr A. Stekolnikov

Zoological Institute RAS

St.Petersburg, RUSSIAN FEDERATION

Corresponding Author Secondary Information:

Corresponding Author's Institution:

Zoological Institute RAS

Corresponding Author's Secondary Institution:

First Author:

Alexandr A. Stekolnikov

First Author Secondary Information: 


\begin{tabular}{|c|c|}
\hline \multirow[t]{5}{*}{ Order of Authors: } & Alexandr A. Stekolnikov \\
\hline & Sonja Matthee \\
\hline & Alida F. Hasiniaina \\
\hline & Ute Radespiel \\
\hline & Lance A. Durden \\
\hline \multicolumn{2}{|c|}{ Order of Authors Secondary Information: } \\
\hline Response to Reviewers: & $\begin{array}{l}\text { "Please download from the website two copies for your edited MS. One (A version) } \\
\text { shows the changes and the other (B version) has them accepted. Could you please } \\
\text { check the changes carefully and provide information or reword text where highlighted. } \\
\text { Please leave the tracking on and highlight any changes you wish to make on the B } \\
\text { version and submit it to the Editorial Manager." } \\
\text { - Done. } \\
\text { "Also make sure you submit to the Editorial Manager the final versions of high quality } \\
\text { figures. Skip this in case you have done so with the first submission of the MS and no } \\
\text { revisions were made." } \\
\text { - High resolution figures are uploaded. Low resolution figures remained at the end of } \\
\text { the Main Document. }\end{array}$ \\
\hline
\end{tabular}




\title{
A new species of Schoutedenichia Jadin \& Vercammen-Grandjean, 1954 from Madagascar and a re-description of S. dutoiti (Radford, 1948) from South Africa (Acariformes: Trombiculidae)
}

Alexandr A. Stekolnikov • Sharon E. Kessler • Sonja Matthee • Alida F. Hasiniaina • Ute Radespiel • Elke Zimmermann • Lance A. Durden

Received: 3 April 2019 / Accepted: 10 August 2019

This article was registered in the Official Register of Zoological Nomenclature (ZooBank) as E5FF7DCC-6728-492C-B374-5F1FAF4A8C94. This article was published as an Online First article on the online publication date shown on this page. The article should be cited by using the doi number. This is the Version of Record.

This article is part of the topical collection Arthropoda.

\author{
A. A. Stekolnikov (corresponding author) \\ Zoological Institute of the Russian Academy of Sciences, Saint Petersburg, Russia \\ e-mail: Alexandr.Stekolnikov@zin.ru

\section{S. E. Kessler} \\ Department of Psychology, University of Stirling, Stirling, Scotland

\section{S. Matthee} \\ Conservation Ecology and Entomology, Stellenbosch University, Stellenbosch, South Africa
}

\author{
A.F. Hasiniaina \\ Faculté des Sciences, Université de Mahajanga, BP 652, Mahajanga, Madagascar
}

\author{
A.F. Hasiniaina • U. Radespiel • E. Zimmermann \\ Institute of Zoology, University of Veterinary Medicine Hannover, Bünteweg 17, 30559 \\ Hannover, Germany
}

L.A. Durden 
Department of Biology, Georgia Southern University, Statesboro, Georgia 30458, USA

\begin{abstract}
A new chigger mite species, Schoutedenichia microcebi $\mathrm{n}$. sp. is described from the grey mouse lemur Microcebus murinus (J.F. Miller) from Madagascar. The new species is closely related to $S$. dutoiti (Radford, 1948), a species described from a single specimen collected on a rodent in South Africa. Examination of the holotype and new material on S. dutoiti from South Africa enabled us to re-describe this species and provide new data on its hosts and geographical distribution.
\end{abstract}

\title{
Introduction
}

There are currently nine known species of chigger mites in Madagascar, of which only one, Trisetica aethiopica (Hirst, 1926), has also been found on the African continent. However, most Madagascan chigger species have close relatives in Africa (Stekolnikov \& Fain, 2004;

Stekolnikov, 2018). A rather large sample of ectoparasites collected from 107 grey mouse lemurs Microcebus murinus (J. F. Miller) in Ankarafantsika National Park by S. E. Kessler and A. F. Hasiniaina included one chigger mite species belonging to the genus Schoutedenichia Jadin \& Vercammen-Grandjean, 1954. Schoutedenichia is a genus belonging to the tribe Schoengastiini which has a worldwide distribution. The last checklist of the Trombiculinae prepared by Vercammen-Grandjean (1965) included 61 species of Schoutedenichia, 46 of which were described from the Afrotropical zoogeographical region. Later, many new species were described from Africa (Stekolnikov, 2018), Australia (Domrow \& Lester, 1985), India (Fernandes \& Kulkarni, 2003), Iran (Stekolnikov et al., 2019), and other regions of the world. Examination of the last revision of this genus (Vercammen-Grandjean, 1958) and all descriptions of its species published later led us to the conclusion that our material belongs to a new species, which is closely related to a little known South African species, Schoutedenichia dutoiti (Radford, 1948). Fortunately, the first author had the opportunity to examine the holotype of $S$. dutoiti held in the Natural History Museum (NHM, London, UK). Moreover, a large sample of $S$. dutoiti was collected from rodents in the Mpumalanga Province of South Africa by S. Matthee and identified by the first author that allowed a reliable morphological comparison of the new species with $S$. dutoiti. 


\section{Materials and methods}

All specimens of the new mite species (parasitic larvae) were collected from wild grey mouse lemurs in Ankarafantsika National Park near the Ampijoroa forestry station ( $\left.16^{\circ} 19^{\prime} \mathrm{S}, 46^{\circ} 48^{\prime} \mathrm{E}\right)$ in Jardin Botanique A (JBA), Madagascar. In total, 107 grey mouse lemurs were trapped in Sherman live traps (H. B. Sherman Traps, Inc., Tallahassee, FL, USA) baited with banana during the dry season (May through November) of 2010 and 2011. Lemurs were removed from traps, restrained by hand, and examined for ectoparasites. We inspected the face, ears, and tail, then parted the fur on the back and legs. Ectoparasites were preserved in $90 \%$ ethanol. Lemurs were fed banana and released at their capture sites at dusk (for details see Kessler et al., 2014, 2018).

New specimens of $S$. dutoiti were collected from rodents by S. Matthee, as reported by Stekolnikov \& Matthee (2019).

Preparation of the new material was completed by V. A. Stekolnikova (specimens of Schoutedenichia microcebi n. sp.) and A. A. Stekolnikov (specimens of S. dutoiti) in the Laboratory of Parasitic Arthropods, Zoological Institute of the Russian Academy of Sciences (ZIN, Saint Petersburg, Russia). Specimens were slide-mounted using Faure-Berlese medium (de Faure's medium), according to standard methodologies (Krantz, 1978). Identification was carried out by A. A. Stekolnikov with the use of a MBI-3 microscope (LOMO plc, St. Petersburg, Russia) with phase contrast optics. Measurements were made with an ocular micrometer; drawings were prepared using a drawing tube. Microphotographs were taken using a Leica DM5000B microscope (Leica Microsystems GmbH, Wetzlar, Germany) connected to a ToupCam 5.1 digital camera, model FMA050 (Hangzhou ToupTek Photonics Co., Ltd, Hangzhou, Zhejiang, China) using differential interference contrast.

The holotype of $S$. dutoiti was examined by A. A. Stekolnikov during his visit to the Natural History Museum, London, in November 2017. The arrangement of the idiosomal setae of this species was drawn using an Olympus BH-2 microscope (Olympus Corporation, Tokyo, Japan) with a camera lucida; measurements were performed using a Zeiss Axiophot microscope (Carl Zeiss AG, Oberkochen, Germany) with an ocular micrometer.

For the description, we have used the standard terminology, abbreviations and diagnostic formulae generally accepted in the taxonomy of trombiculids (Goff et al., 1982, Stekolnikov, 2018). All measurements are given in micrometres. Intervals of variation are bracketed in the formulae for the arrangement of dorsal idiosomal setae (fD); square brackets mark the first (double) row; plus signs separate the total number of caudal setae which cannot be unambiguously divided into rows. In the schemes of the dorsal idiosomal setae arrangement, dotted lines outline tentative boundaries between rows of setae. The double circles in the figures 
of the legs represent the bases of unspecialised tactile setae; single circles correspond to the unspecialised setae situated on the opposite side of the leg.

The holotype of the new species, as well as the additional material of S. dutoiti, is deposited in the Zoological Institute of the Russian Academy of Sciences, Saint Petersburg, Russia (ZIN); paratypes will be deposited in ZIN and the Natural History Museum, London, UK (NHM)

\section{Schoutedenichia (Schoutedenichia) microcebi Stekolnikov n. sp.}

Type-host: Microcebus murinus (J.F. Miller) (Primates: Cheirogaleidae), grey mouse lemur. Type material: Larval holotype (ZIN, 11007, T-Tr.-85) ex Microcebus murinus, female No. 0411, sample 120 5/3, Madagascar, Boeny Region, Ankarafantsika National Park, Jardin Botanique A, 14.viii.2011, collected by S.E. Kessler and A.F. Hasiniaina; 71 larval paratypes (ZIN, 1098711057) ex 12 specimens of M. murinus, same locality, 11.vi.2011 and 13.vi.2011, 22.vii.2011 and 26.vii.2011, 14.viii.2011 and 16.viii.2011, collected by S. E. Kessler and A. F. Hasiniaina. ZooBank registration: The Life Science Identifier (LSID) for Schoutedenichia (Schoutedenichia) microcebi n. sp. is urn:1sid:zoobank.org:act:17FE3F94-9F3A-45D1-9222-F1274A468C4E. Etymology: The new species name refers to the host genus.

Description (Figs 1-14)

Larva [Based on the holotype and 11 paratypes (nos 10991, 10997, 10998, 11001/1, 11022, 11026, 11032, 11044, 11049, 11054, 11055); measurements are given in Table 1.] Idiosoma (Figs. 2-5, 8, 9). Eyes $2+2$. Two pairs of humeral setae and 38-44 moderately barbed dorsal idiosomal setae; always $8(6+2)$ setae in 1st row, 10 setae in 2 nd row, and 8 setae in 3rd row; 6 setae in 4th row in 6 specimens and 4 setae in 4 specimens; distribution of caudal setae by rows is uncertain; formula of humeral and dorsal idiosomal setae of holotype $\mathrm{fD}=4 \mathrm{H}-[6-2]-10-8-6-4-$ 4-2-2; 4 sternal setae; 32-40 ventral setae; total number of idiosomal setae (NDV), excluding coxal and sternal, 75-83.

Gnathosoma (Figs. 6, 7, 11). Cheliceral blade with tricuspid cap; proximal half of cheliceral base with small puncta; gnathobase bears one pair of branched setae; galeal setae nude; palpal claw with 3 prongs (Fig. 11); palpal femoral and genual setae with long branches; dorsal and lateral palpal tibial setae nude, ventral palpal tibial seta branched; palpal tarsus with 4 branched setae, nude subterminala, and basal tarsala. 
Scutum (Figs. 1, 8, 10). Nearly trapezoidal, wider than long, with sinuous anterior margin and deeply bilobate posterior margin, with small, rather sparse puncta and irregular cracks in all specimens examined; AM at level of ALs; sensillary bases slightly anterior to level of PLs (PSB - $\mathrm{P}-\mathrm{PL}=3-7) ; \mathrm{PL}>\mathrm{AL}>\mathrm{AM} ; \mathrm{AM}$ and ALs with long thin barbs, PLs barbed similar to dorsal idiosomal setae; sensilla nearly globose, covered with pointed scales.

Legs (Figs. 12-14). All legs 7-segmented, with 1 pair of claws and claw-like empodium. Leg I: coxa with 1 non-specialised branched seta (1B); trochanter 1B; basifemur 1B; telofemur 5B; genu 4B, 2 genualae, microgenuala; tibia 8B, 2 tibialae, microtibiala; tarsus 22B, tarsala, microtarsala at level of tarsala, subterminala, parasubterminala, pretarsala. Leg II: coxa 1B; trochanter 1B; basifemur 2B; telofemur 4B; genu 3B, genuala; tibia 6B, 2 tibialae; tarsus 16B, tarsala, microtarsala at level of tarsala, pretarsala. Leg III: coxa 1B; trochanter 1B; basifemur 2B; telofemur 3B; genu 3B, genuala; tibia 6B; tarsus 15B.

Diagnosis

$\mathrm{SIF}=4 \mathrm{BS}-\mathrm{N}-3-2110.0000 ; \mathrm{fsp}=7.7 .7 ; \mathrm{fCx}=1.1 .1 ; \mathrm{fSt}=2.2 ; \mathrm{fPp}=\mathrm{B} / \mathrm{B} / \mathrm{NNB} ; \mathrm{fSc}: \mathrm{PL}>\mathrm{AL}>$ $\mathrm{AM} ; \mathrm{Ip}=609-664 ; \mathrm{fD}=4 \mathrm{H}-[6-2]-10-8-6(4)+(6-12) ; \mathrm{DS}=42-48 ; \mathrm{VS}=32-40 ; \mathrm{NDV}=75-83$.

Differential diagnosis

The new species is similar to Schoutedenichia dutoiti (Radford, 1948) and differs from it in having fewer idiosomal setae (DS $=42-48$, VS $=32-40$, and NDV $=75-83$ vs 70-94, 55-76, and 135-166, respectively); fD = 4H-[6-2]-10-8-6(4)+(6-12) vs 4H-[8(9)-4(5)]-(15-18)-(10$13)+(19-30)$; a shorter scutum $(\mathrm{ASB}=19-22 \mu \mathrm{m} ; \mathrm{PSB}=12-15 \mu \mathrm{m} ; \mathrm{SD}=33-37 \mu \mathrm{m}$; and AP = 23-26 vs 28-31 $\mu \mathrm{m}, 20-23 \mu \mathrm{m}, 49-53 \mu \mathrm{m}$, and 37-41 $\mu \mathrm{m}$, respectively); in having deeply bilobate posterior scutal margin $v s$ slightly bilobate; in having sensillary bases situated slightly anterior to level of PLs $v s$ far anterior (PSB-P-PL = 3-7 vs 13-16 $\mu \mathrm{m}$ ); in AL $\geq$ PL vs PL > AL; in having long thin barbs of AM and ALs vs AM and ALs barbed similar to PLs and dorsal idiosomal setae; in the absence of additional hook of cheliceral blade; in the absence of puncta on gnathobase and palpal femur; and in having shorter legs (Ip = 609-664 vs 792-846 $\mu \mathrm{m}$ ).

The new species differs from the three species of Schoutedenichia (Schoutedenichia) previously described in Madagascar, as follows: (i) from S. gigantica Vercammen-Grandjean \& Watkins, 1965 and S. tiptoni Vercammen-Grandjean \& Watkins, 1965: by its smaller size (e.g. Ip $=609-664 \mu \mathrm{m}$ in S. microcebi, 1,400 $\mu \mathrm{m}$ in S. gigantica, and $992 \mu \mathrm{m}$ in S. tiptoni; $\mathrm{PW}=64-80$ $\mu \mathrm{m}$ in S. microcebi, $119 \mu \mathrm{m}$ in S. gigantica and $107 \mu \mathrm{m}$ in S. tiptoni; PL $=36-41 \mu \mathrm{m}$ in $S$. 
microcebi, $137 \mu \mathrm{m}$ in S. gigantica, and $88 \mu \mathrm{m}$ in S. tiptoni); in having fewer idiosomal setae (NDV $=75-83$ vs 140 in S. gigantica and 194 in S. tiptoni), and in the presence of usual two posterior sternal setae vs $10(6+4)$ (Vercammen-Grandjean \& Watkins, 1965). The new species also differs from $S$. gigantica by the absence of large hooks of heliceral blades and from $S$. tiptoni by the presence of one seta on coxa III vs 3-4 setae; (ii) from S. subterranea Stekolnikov $\&$ Fain, 2004: by the presence of bilobate posterior margin of the scutum $v s$ concave; different proportions of the scutum ( $\mathrm{AP}=23-26 v s 40$ ); normally developed eyes $v s$ nearly reduced; heavily barbed idiosomal setae $v s$ having a few short barbs in S. subterranea; in having longer scutal setae $(\mathrm{AM}=22-27 \mu \mathrm{m}, \mathrm{AL}=30-36 \mu \mathrm{m}$ and $\mathrm{PL}=36-41$ vs $16-18 \mu \mathrm{m}, 16-22 \mu \mathrm{m}$ and 29-30 $\mu \mathrm{m}$, respectively); and in having fewer idiosomal setae (NDV $=75-83$ vs $102-107$ ).

\section{Schoutedenichia (Schoutedenichia) dutoiti (Radford, 1948)}

Syns Ascoschöngastia dutoiti Radford, 1948; Euschöngastia dutoiti of Wharton \& Fuller (1952)

Hosts: Saccostomus campestris Peters (Rodentia: Nesomyidae) (Radford 1948). Aethomys ineptus (Thomas \& Wroughton), Gerbilliscus leucogaster (Peters), Mastomys natalensis Smith, and Rattus tanezumi Temminck (Rodentia: Muridae) (present study).

Type-material examined: Larval holotype (NHM 1948.2.3.30; labeled as "lectotype" by the hand of Radford) ex Saccostomus campestris, Albany, C[ape] P[rovince], Palmers Dam (unknown locality in the Western Cape Province of South Africa), 23 April [19]39, [Collector] Dr. G. Theiler.

Additional material examined: 44 larvae (ZIN 9968-10390) from South Africa, Mpumalanga Province, collector S. Matthee: 9 larvae from ears of two A. ineptus (MNRAeth2 and MNRT16),

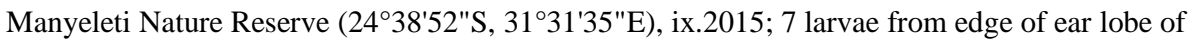
G. leucogaster (ThT11), Hlavekisa village (24³7'51"S, 31²2'42"E), ix.2015; 17 larvae from edge of ear lobe of five M. natalensis (GbGMas13, GbGMas14, GbGMas15, GbGMas17, GbgMas9), Gottenburg village (243'01"S, 3125'19"E), ix.2015; 3 larvae from ear lobe of $M$. natalensis (HlvMas3), Hlavekisa, ix.2015; 8 larvae from edge of ear lobe of R. tanezumi (GbGMas16), Gottenburg, ix.2015.

Distribution: South Africa: Western Cape Province and Mpumalanga Province (present study).

Redescription (Figs. 15-31) 
Larva [Based on the holotype and 8 specimens from the additional material (nos 9971, 99739975, 10215, 10387, 10389, 10214 - figure of cheliceral blades only); metrical data are given in Table 1.] Idiosoma (Figs. 16-20, 24, 25). Eyes $2+2$. Two pairs of humeral setae and 70-94 moderately barbed dorsal idiosomal setae; $12-14$ setae in 1st row, $15-18$ setae in 2nd row, and 10-13 setae in 3rd row; distribution of posterior 19-30 setae by rows is uncertain; formula of humeral and dorsal idiosomal setae of holotype $\mathrm{fD}=4 \mathrm{H}-[8-4]-14-12-11+17 ; 4$ sternal setae; $55-$ 76 ventral setae; total number of idiosomal setae (NDV), excluding coxal and sternal, 135-166.

Gnathosoma (Figs. 21-23). Cheliceral blade with tricuspid cap and additional hook (Fig. 23); proximal half of cheliceral base with large puncta; gnathobase and palpal femur with puncta; gnathobase bearing one pair of branched setae; galeal setae nude; palpal claw with 3 prongs; palpal femoral and genual setae with long branches; dorsal and lateral palpal tibial setae nude, ventral palpal tibial seta with few long branches; palpal tarsus with 4 branched setae, nude subterminala, and basal tarsala.

Scutum (Figs. 15, 24, 26). Nearly trapezoidal, wider than long, with sinuous anterior margin and slightly bilobate posterior margin, with small puncta; AM at level of ALs; sensillary bases far anterior to level of PLs (PSB - P-PL = 13-16); AL $\geq \mathrm{PL}>\mathrm{AM}$; all scutal setae barbed similar to dorsal idiosomal setae; sensilla nearly globose, covered with pointed scales.

Legs (Figs. 27-31). All legs 7-segmented, with 1 pair of claws and claw-like empodium. Leg I: coxa with 1 non-specialised branched seta (1B); trochanter 1B; basifemur 1B; telofemur 5B; genu 4B, 2 genualae, microgenuala; tibia 8B, 2 tibialae, microtibiala; tarsus 22B, tarsala, microtarsala slightly posterior to tarsala, subterminala, parasubterminala, pretarsala. Leg II: coxa 1B; trochanter 1B; basifemur 2B; telofemur 4B; genu 3B, genuala; tibia 6B, 2 tibialae; tarsus 16B, tarsala, microtarsala posterior to tarsala, pretarsala. Leg III: coxa 1B; trochanter 1B; basifemur 2B; telofemur 3B; genu 3B, genuala; tibia 6B; tarsus $15 \mathrm{~B}$.

\section{Diagnosis}

$\mathrm{SIF}=4 \mathrm{BS}-\mathrm{N}-3-2110.0000 ; \mathrm{fsp}=7.7 .7 ; \mathrm{fCx}=1.1 .1 ; \mathrm{fSt}=2.2 ; \mathrm{fPp}=\mathrm{B} / \mathrm{B} / \mathrm{NNB} ; \mathrm{fSc}: \mathrm{AL} \geq \mathrm{PL}>$ AM; Ip = 792-846; fD = 4H-[8(9)-4(5)]-(15-18)-(10-13)+(19-30); DS = 70-94; VS = 55-76; $\mathrm{NDV}=135-166$.

Remarks

This species was described from a single specimen. Vercammen-Grandjean (1958), in his revision of the genus Schoutedenichia, reproduced data from the original description of $S$. dutoiti. He did not see the holotype, but prepared new drawings, which were based on the 
illustrations made by Radford (1948). He also gave the exact numbers of dorsal and ventral idiosomal setae, obviously, on the base of an examination of the figure in the original description. There are 88 setae in the dorsal view of the idiosoma, including humeral setae, and 74 setae in the ventral view, excluding sternal and coxal setae (figures 11-12 in Radford, 1948). According to Vercammen-Grandjean (1958), $\mathrm{fD}=88$ and $\mathrm{fV}=70$; presumably, he assumed that 4 caudal setae were depicted by Radford twice, in dorsal and ventral views. The numbers of setae given in the original description are approximate: "about ninety" and "about seventy-six" Radford (1948, p. 218). According to our examination of the holotype, DS is 70 and VS is 65 in this specimen.

\section{Discussion}

Schoutedenichia microcebi $\mathrm{n}$. sp. is the fourth species of Schoutedenichia recorded from Madagascar, after S. gigantica, S. tiptoni and S. subterranea. However, this represents the first chigger species found parasitising lemurs in Madagascar: previously known Madagascan chiggers were collected from species of Rodentia, Afrosoricida, Anura and Squamata. Generally, records of Schoutedenichia from primates are few: two species, S. evansi Vercammen-

Grandjean, 1958 and S. zanzibarica Vercammen-Grandjean, 1958, were described from Galago senegalensis É. Geoffroy in Tanzania and S. potto Vercammen-Grandjean \& Yang, 1964 was described from Perodicticus potto ibeanus Thomas in the Democratic Republic of the Congo (Stekolnikov, 2018). Thus, all known primate hosts of Schoutedenichia belong to the same suborder, Strepsirrhini, which includes lemuriform and lorisiform primates from Madagascar, Africa, India and Southeast Asia.

A recently published survey of ectoparasite communities of two Microcebus É. Geoffroy species (Klein et al., 2018) reported the presence of trombiculid larvae on both M. murinus and M. ravelobensis (Zimmermann, Cepok, Rakotoarison, Zietemann \& Radespiel) at the same locality in Ankarafantsika National Park, but the mites were not identified. The second species is a recently described lemur that occurs sympatrically with M. murinus (see Zimmermann et al., 1998). Therefore, it is expected to be parasitised by the same species of trombiculids, since these mites, which are parasites in the larval stage only, are more habitat-, than host-specific (Kudryashova, 1998).

Acknowledgements We are grateful to the Malagasy government, Ministère de l'Environnement, de l'Ecologie, et des Forêts, and Madagascar National Parks (MNP) for their 
permission to work in the Ankarafantsika National Park. We would like to thank Professor Solofonirina Rasoloharijaona, Professor Blanchard Randrianambinina and the Faculté des Sciences, Université de Mahajanga for assistance and training. We also thank Jean de la Croix and Johnny Kennedy for their guide services in the park. The reserve manager (Manyeleti), field and technical assistants and postgraduate students are thanks for their help and support during fieldwork in Mpumalanga Province, South Africa. We are grateful to Jan Beccaloni, curator of the collection of Arachnida at NHM, for her valuable assistance during the visit of A.A. Stekolnikov to the Museum. The first author appreciates his wife, Victoria A. Stekolnikova (ZIN), for her skilled help in slide preparation. Sadly, our co-author Elke Zimmermann passed away during the process of publishing the article. We will forever keep the memory of her as an outstanding researcher on Malagasy wildlife.

Funding This work was funded by the Russian Foundation for Basic Research (grant number 16-04-00145-a, to A.A. Stekolnikov); PEO Scholar Award, NSF Dissertation Improvement Grant (\#0961779), Lewis and Clark Fund of the American Philosophical Society, the Animal Behaviour Society, Sigma Xi (National Chapter, grant \#G2009101504), Sigma Xi (Arizona State University chapter), American Society of Primatologists, Arizona State University School of Human Evolution and Social Change, the Arizona State University Graduate and Professional Student Association (to S.E. Kessler); Stellenbosch University and the National Research Foundation (South Africa) (grant number GUN 85718, to S. Matthee); and the University of Veterinary Medicine Hannover (to A.F. Hasiniaina, U. Radespiel, and E. Zimmermann).

\section{Compliance with ethical standards}

Conflict of interest The authors declare that they have no conflict of interests.

Ethical approval The study was approved by Madagascar National Parks (2010 permits: N102/10/MEF/ SG/DGF/DCB.SAP /SCBSE, N103/10/MEF/SG/DGF/DCB.SAP/ SCBSE; 2011 permits: N101/11/MEF/SG/DGF /DCB.SAP/SCB, N102/11/MEF/SG/DGF/DCB.SAP/SCB) and the Arizona State University Institutional Animal Care and Use Committee (Protocol: 101077R). Fieldwork in Mpumalanga was approved by Mpumalanga Tourism and Parks Agency (permit number ES 5/14), Department of Agriculture, Forestry and Fisheries (Reference number 12/11/1/7/5) and the Animal Ethics Committees of Stellenbosch University (Reference number SU-ACM11- 00004) and Pretoria University (Reference number V046-14). 


\section{References}

Domrow, R. \& Lester, L. N. (1985). Chiggers of Australia (Acari: Trombiculidae): an annotated checklist, keys and bibliography. Australian Journal of Zoology, Supplementary Series, $114,1-111$

Fernandes S.J., S., \& Kulkarni, S. M. (2003). Studies on the trombiculid mite fauna of India. Records of the Zoological Survey of India, Occasional Paper 212.

Goff, M. L., Loomis, R. B., Welbourn, W. C., \& Wrenn, W. J. (1982). A glossary of chigger terminology (Acari: Trombiculidae). Journal of Medical Entomology, 19, 221-238.

Kessler, S. E., Radespiel, U., Hasiniaina, A., Leliveld, L., Nash, L. T., Zimmermann, E., \& Radespiel, U. (2014). Modeling the origins of mammalian sociality: Moderate evidence for matrilineal signatures in mouse lemur vocalizations. Frontiers in Zoology, 11, 14.

Kessler, S. E., Radespiel, U., Hasiniaina, A. I. F., Nash, L. T., \& Zimmermann, E. (2018). Does the grey mouse lemur use agonistic vocalisations to recognise kin? Contributions to Zoology, 87, 261-274.

Klein, A., Zimmermann, E., Radespiel, U., Schaarschmidt, F., Springer, A., \& Strube C. (2018). Ectoparasite communities of small-bodied Malagasy primates: seasonal and socioecological influences on tick, mite and lice infestation of Microcebus murinus and M. ravelobensis in northwestern Madagascar. Parasites \& Vectors, 11, 459.

Krantz, G. W. (1978). A manual of acarology. 2nd ed. Corvallis: Oregon State University Book Stores.

Kudryashova, N. I. (1998). Chigger Mites (Acariformes, Trombiculidae) of the East Palaearctic. (In Russian). Moscow: KMK Scientific Press.

Radford, C. D. (1948). New larval mites (Acarina: Trombiculidae and Leeuwenhoekidae) from African hosts. Journal of Zoology, 118, 213-222.

Stekolnikov, A. A. (2018). Taxonomy and distribution of African chiggers (Acariformes, Trombiculidae). European Journal of Taxonomy, 395, 1-233.

Stekolnikov, A. A., \& Fain, A. (2004). A new genus and four new species of chigger mites (Acari Trombiculidae) from Madagascar. Belgian Journal of Entomology, 6, 337-352. Stekolnikov, A. A., \& Matthee, S. (2019). Six new and one little known species of chigger mites (Acariformes: Trombiculidae) from South Africa. Systematic \& Applied Acarology, 24, 435-466. 
Stekolnikov, A. A., Saboori, A., Shamsi, M., \& Hakimitabar, M. (2019). Chigger mites

(Acariformes: Trombiculidae) of Iran. Zootaxa, 4549, 1-66.

Vercammen-Grandjean, P. H. (1958). Revision du genre Schoutedenichia Jad. et Verc. Annales du Musée Royal du Congo Belge, Serie in 8, 65, 1-103.

Vercammen-Grandjean, P. H. (1965). Trombiculinae of the World. Synopsis with Generic, Subgeneric, and Group Diagnoses (Acarina, Trombiculidae). San Francisco: George Williams Hooper Foundation.

Vercammen-Grandjean, P. H., \& Watkins, S. G. (1965). Schoutedenichia gigantica and S. tiptoni, two new and extraordinary species from Madagascar (Acarina: Trombiculidae). Acarologia, 7, 683-694.

Wharton, G. W., \& Fuller, H. S. (1952). A manual of the chiggers. Memoirs of the Entomological Society of Washington, 4, 1-185.

Zimmermann, E., Cepok, S., Rakotoarison, N., Zietemann, V. \& Radespiel, U. (1998). Sympatric mouse lemurs in north-west Madagascar: a new rufous mouse lemur species (Microcebus ravelobensis). Folia Primatologica, 69, 106-114.

\section{Legends to figures}

Figs. 1-7 Schoutedenichia microcebi n. sp., larva. 1, Scutum and eyes of holotype (one sensillum missing); 2, Arrangement of dorsal idiosomal setae of holotype; 3, Arrangement of ventral idiosomal setae of holotype; 4, Dorsal idiosomal seta of holotype; 5 , Ventral preanal idiosomal seta of holotype; 6, Dorsal aspect of gnathosoma of paratype ZIN 10997 (only two prongs of the palpal claw are visible); 7, Ventral aspect of gnathosoma of paratype ZIN 10997 (only two prongs of the palpal claw are visible). Abbreviations: AM, anteromedian scutal seta; AL, anterolateral scutal seta; Ch, cheliceral blade; Ga, galeal seta; gns, gnathocoxal seta; PC, palpal claw; H, humeral setae; PF, palpal femur; PG, palpal genu; PL, posterolateral scutal seta; PTa, palpal tarsus; PTi, palpal tibia; sens, sensillum; SB, sensillary base. Scale-bars: 1, $50 \mu \mathrm{m} ; 2$, $3,100 \mu \mathrm{m} ; 4-7,20 \mu \mathrm{m}$

Figs. 8-11 Schoutedenichia microcebi n. sp., larva. 8, Holotype, dorsal aspect of idiosoma (one sensillum missing); 9, Holotype, sternal area of idiosoma; 10, Paratype ZIN 11022, scutum (sensilla missing); 11, paratype ZIN 11022, palpal claw. Abbreviations: AM, anteromedian scutal seta; AL, anterolateral scutal seta; $\mathrm{D}_{1}$, dorsal idiosomal setae of 1st row; cxI, coxa I; cxII, coxa II; cxIII, coxa III; H, humeral setae; ic, infracapitulum (gnathobase); PL, posterolateral 
scutal seta; sens, sensillum; SB, sensillary base; sta, anterior sternal setae; stp, posterior sternal setae; V, ventral setae. Scale-bars: 8, 9, $50 \mu \mathrm{m} ; 10,20 \mu \mathrm{m} ; 11,5 \mu \mathrm{m}$

Figs. 12-14 Schoutedenichia microcebi n. sp., larva paratype ZIN 10998. 12, Free part of leg I (trochanter-tarsus); 13, Free part of leg II (trochanter-tarsus); 14, Free part of leg III (trochantertarsus). Abbreviations: $\mathrm{f}_{1}$, famulus I; $\mathrm{f}_{2}$, famulus II; ga, genuala I; gm, genuala II; gp, genuala III; mga, microgenuala; mta, microtibiala; pST, parasubterminala; PT", pretarsala I; PT", pretarsala II; $S_{1}$, tarsala I; $S_{2}$, tarsala II; ST, subterminala; ta, tibiala I; tm, tibiala II. Scale-bars: $50 \mu \mathrm{m}$

Figs. 15-23 Schoutedenichia dutoiti, larva. 15, Scutum and eyes of specimen ZIN 9974; 16, Humeral seta of specimen ZIN 9974; 17, Dorsal idiosomal seta of specimen ZIN 9974; 18, Ventral preanal idiosomal seta of specimen ZIN 9974; 19, Arrangement of dorsal idiosomal setae of holotype; 20, Arrangement of ventral idiosomal setae of holotype; 21, Dorsal aspect of gnathosoma of specimen ZIN 9970; 22, Ventral aspect of gnathosoma of specimen ZIN 9970; 23, Ventrolateral view of cheliceral blades of specimen ZIN 10214. Abbreviations: AM, anteromedian scutal seta; AL, anterolateral scutal seta; Ch, cheliceral blade; Ga, galeal seta; gns, gnathocoxal seta; PC, palpal claw; H, humeral setae; PF, palpal femur; PG, palpal genu; PL, posterolateral scutal seta; PTa, palpal tarsus; PTi, palpal tibia; sens, sensillum; S, palpal subterminala; $\mathrm{S}_{0}$, palpal tarsala; SB, sensillary base. Scale-bars: 15, $50 \mu \mathrm{m} ; 16-18,21-23,20$ $\mu \mathrm{m}, 19,20,100 \mu \mathrm{m}$

Figs. 24-26 Schoutedenichia dutoiti, larva ZIN 10389. 24, Scutum and dorsal idiosomal setae (one sensillum missing). 25, Sternal area of idiosoma. 26, Scutum and eyes (one sensillum missing) Abbreviations: AM, anteromedian scutal seta; $\mathrm{AL}$, anterolateral scutal seta; $\mathrm{D}_{1}$, dorsal idiosomal setae of $1^{\text {st }}$ row; cxI, coxa I; cxII, coxa II; cxIII, coxa III; H, humeral setae; ic, infracapitulum (gnathobase); PL, posterolateral scutal seta; sens, sensillum; SB, sensillary base; sta, anterior sternal setae; stp, posterior sternal setae; V, ventral setae. Scale-bars: 24, 25, $50 \mu \mathrm{m}$; $26,20 \mu \mathrm{m}$

Figs. 27-31 Schoutedenichia dutoiti, larva ZIN 9974. 27, Telofemur, genu, tibia, and tarsus of leg I; 28, Trochanter and basifemur of leg I; 29, Free part of leg II (trochanter-tarsus); 30, Trochanter and basifemur of leg III; 31, Telofemur, genu, tibia, and tarsus of leg III. Abbreviations: $\mathrm{f}_{1}$, famulus I; $\mathrm{f}_{2}$, famulus II; ga, genuala I; gm, genuala II; gp, genuala III; mga, microgenuala; mta, microtibiala; pST, parasubterminala; PT', pretarsala I; PT", pretarsala II; $\mathrm{S}_{1}$, tarsala I; $\mathrm{S}_{2}$, tarsala II; ST, subterminala; ta, tibiala I; tm, tibiala II. Scale-bars: $50 \mu \mathrm{m}$ 
1

2

3

4

5

9

10

11

12

13

14

15

16

17

18

19

20

21

22

23

24

25

26

27

28

29

30

31

32

33

34

35

36

37

38

39

40

41

42

43

44

45

46

47

48

49

50

51

52

53

54

55

56

57

58

59

60

61

62

63

64

65 
Table 1 Measurements and counts for Schoutedenichia microcebi n. sp. and S. dutoiti

\begin{tabular}{|c|c|c|c|c|c|c|c|}
\hline & \multicolumn{3}{|c|}{ S. microcebi $(\mathrm{n}=12)$} & \multicolumn{2}{|c|}{ S. dutoiti $(\mathrm{n}=7)$} & \multicolumn{2}{|c|}{ S. dutoiti (holotype) } \\
\hline & Range & Mean & Holotype & Range & Mean & Present study & Radford (1948) \\
\hline $\mathrm{AW}$ & $47-56$ & 50 & 48 & $57-63$ & 60 & 56 & 56 \\
\hline PW & $64-80$ & 72 & 64 & $79-90$ & 83 & 78 & 80 \\
\hline SB & $26-34$ & 31 & 28 & $35-43$ & 40 & 39 & 46 \\
\hline ASB & $19-22$ & 21 & 20 & $29-31$ & 30 & 28 & 30 \\
\hline PSB & $12-15$ & 14 & 13 & $20-23$ & 21 & 21 & 17 \\
\hline SD & $33-37$ & 35 & 33 & $49-53$ & 51 & 49 & 47 \\
\hline P-PL & $7-13$ & 10 & 9 & $6-9$ & 7 & - & - \\
\hline AP & $23-26$ & 25 & 23 & $37-41$ & 39 & 40 & 40 \\
\hline $\mathrm{AM}$ & $22-27$ & 25 & - & $27-30$ & 29 & 27 & 27 \\
\hline $\mathrm{AL}$ & $30-36$ & 33 & 32 & $36-43$ & 40 & 36 & 33 \\
\hline PL & $36-41$ & 38 & 41 & $33-42$ & 38 & 39 & 42 \\
\hline $\mathrm{S}$ & $25-30$ & 28 & - & $31-39$ & 36 & - & 30 \\
\hline $\mathrm{H}$ & $30-34$ & 32 & 33 & $39-43$ & 41 & 44 & - \\
\hline$D_{\min }$ & $20-24$ & 23 & 23 & $25-28$ & 27 & - & - \\
\hline$D_{\max }$ & $25-29$ & 27 & 27 & $31-35$ & 33 & - & - \\
\hline $\mathrm{V}_{\min }$ & $18-22$ & 20 & 18 & $21-23$ & 22 & - & - \\
\hline $\mathrm{V}_{\max }$ & $24-29$ & 26 & 25 & $30-34$ & 32 & - & - \\
\hline pa & $202-241$ & 225 & 225 & $277-297$ & 289 & 254 & - \\
\hline $\mathrm{pm}$ & $185-200$ & 191 & 191 & $234-252$ & 243 & - & - \\
\hline $\mathrm{pp}$ & 209-227 & 219 & 214 & $275-301$ & 286 & - & - \\
\hline Ip & $609-664$ & 634 & 630 & $792-846$ & 817 & - & - \\
\hline DS & $42-48$ & 44 & 48 & 77-94 & 84 & 70 & $c .90$ \\
\hline VS & $32-40$ & 35 & 32 & $55-76$ & 67 & 65 & $c .76$ \\
\hline NDV & $75-83$ & 79 & 80 & $137-166$ & 151 & 135 & $c .166$ \\
\hline TaIIIL & $51-58$ & 56 & 54 & 70-77 & 73 & - & - \\
\hline TaIIIW & $13-14$ & 13 & 14 & $16-17$ & 16 & - & - \\
\hline$S_{1}$ & $10-12$ & 11 & 12 & $21-21$ & 21 & - & - \\
\hline $\mathrm{S}_{2}$ & 14-16 & 15 & 16 & $19-19$ & 19 & - & - \\
\hline
\end{tabular}

Abbreviations: $\mathrm{AW}$, distance between anterolateral scutal setae; $\mathrm{PW}$, distance between posterolateral scutal setae; SB, distance between sensillary bases; ASB, distance from the level of sensillary bases to extreme anterior margin of scutum; PSB, distance from the level of sensillary bases to extreme posterior margin of scutum; SD, length of scutum (ASB + PSB); P-PL, distance from the level of posterolateral scutal setae to extreme posterior margin of scutum; AP, distance between antero- and posterolateral scutal seta on one side; AM, length of anteromedian scutal seta; AL, length of anterolateral scutal setae; PL, length of posterolateral scutal setae; S, length of sensilla; $\mathrm{H}$, length of humeral setae; $D_{\min }$, length of the shortest dorsal idiosomal seta; $D_{\max }$, length of the longest dorsal idiosomal seta; $\mathrm{V}_{\min }$, length of the shortest ventral idiosomal seta; $\mathrm{V}_{\max }$, length of the longest ventral idiosomal seta; pa, length of leg I (including coxa); pm, length of leg II (including coxa); pp, length of leg III (including coxa); Ip, sum of leg lengths ( $\mathrm{pa}+\mathrm{pm}+\mathrm{pp}$ ); DS, number of dorsal idiosomal setae (including humeral); VS, number of ventral idiosomal 
setae (excluding coxal and sternal); NDV, number of idiosomal setae (DS + VS); TaIIIL, length of leg tarsus III; TaIIIW, width of leg tarsus III; $\mathrm{S}_{1}$, length of tarsala I; $\mathrm{S}_{2}$, length of tarsala II 


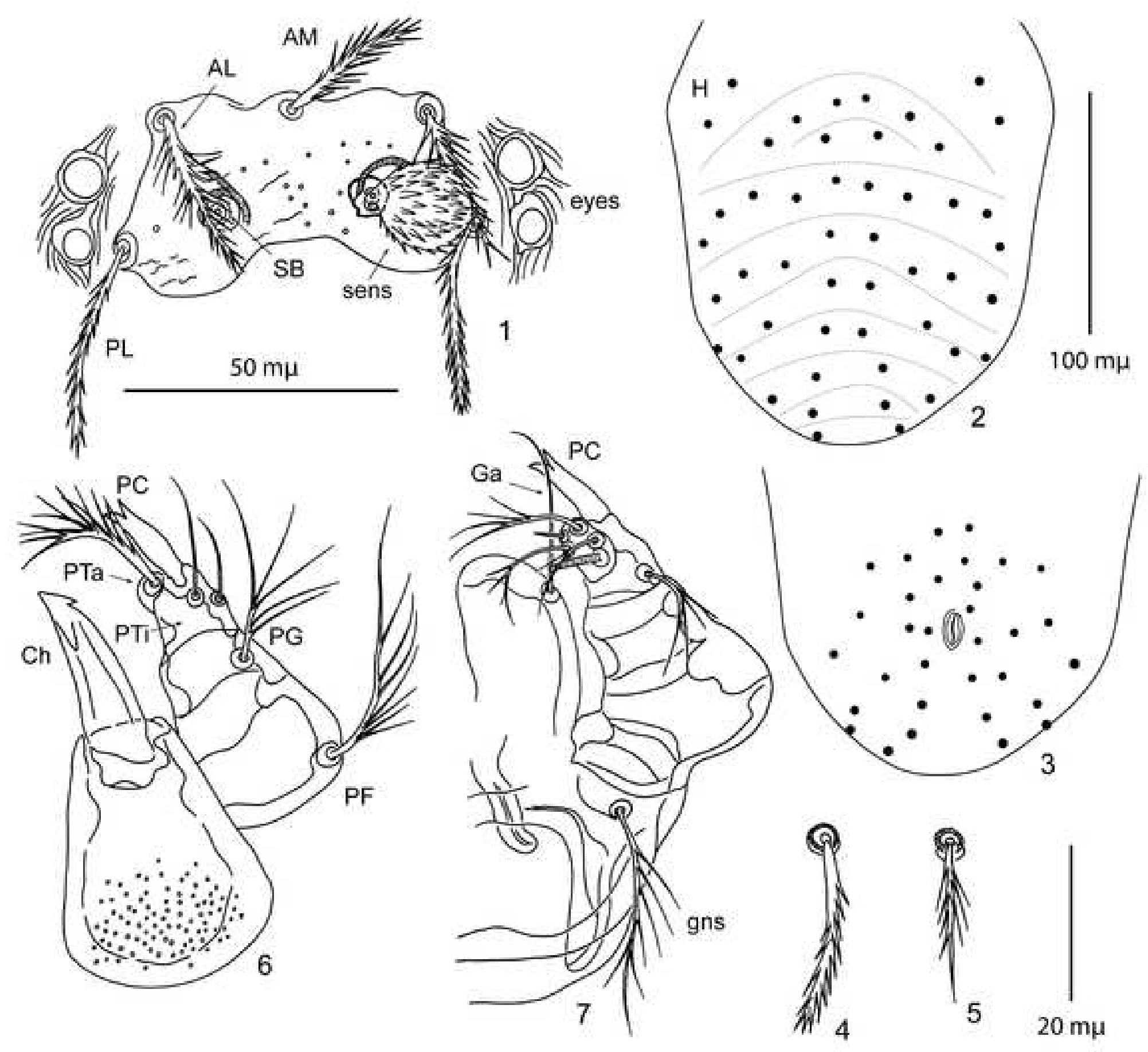



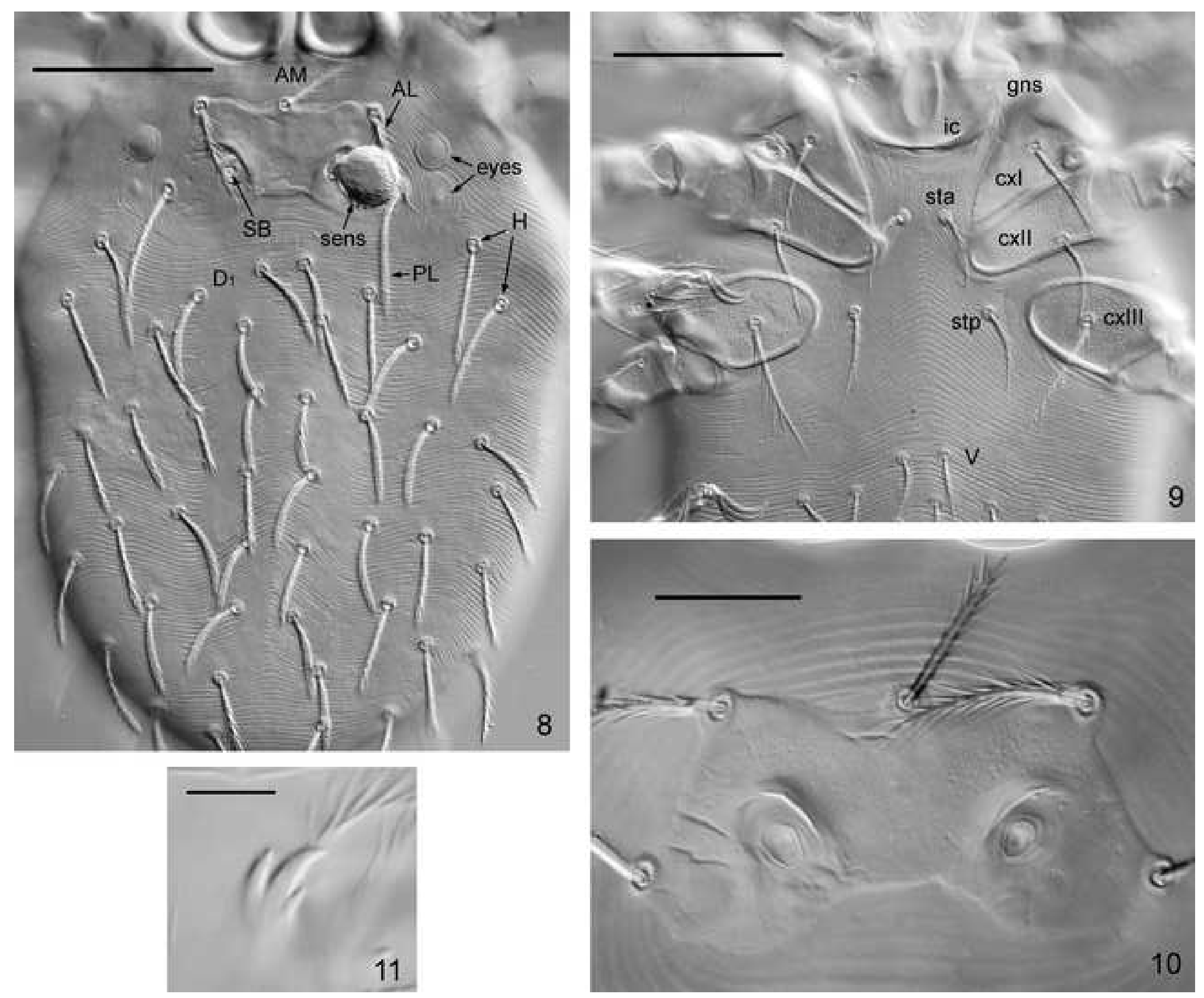


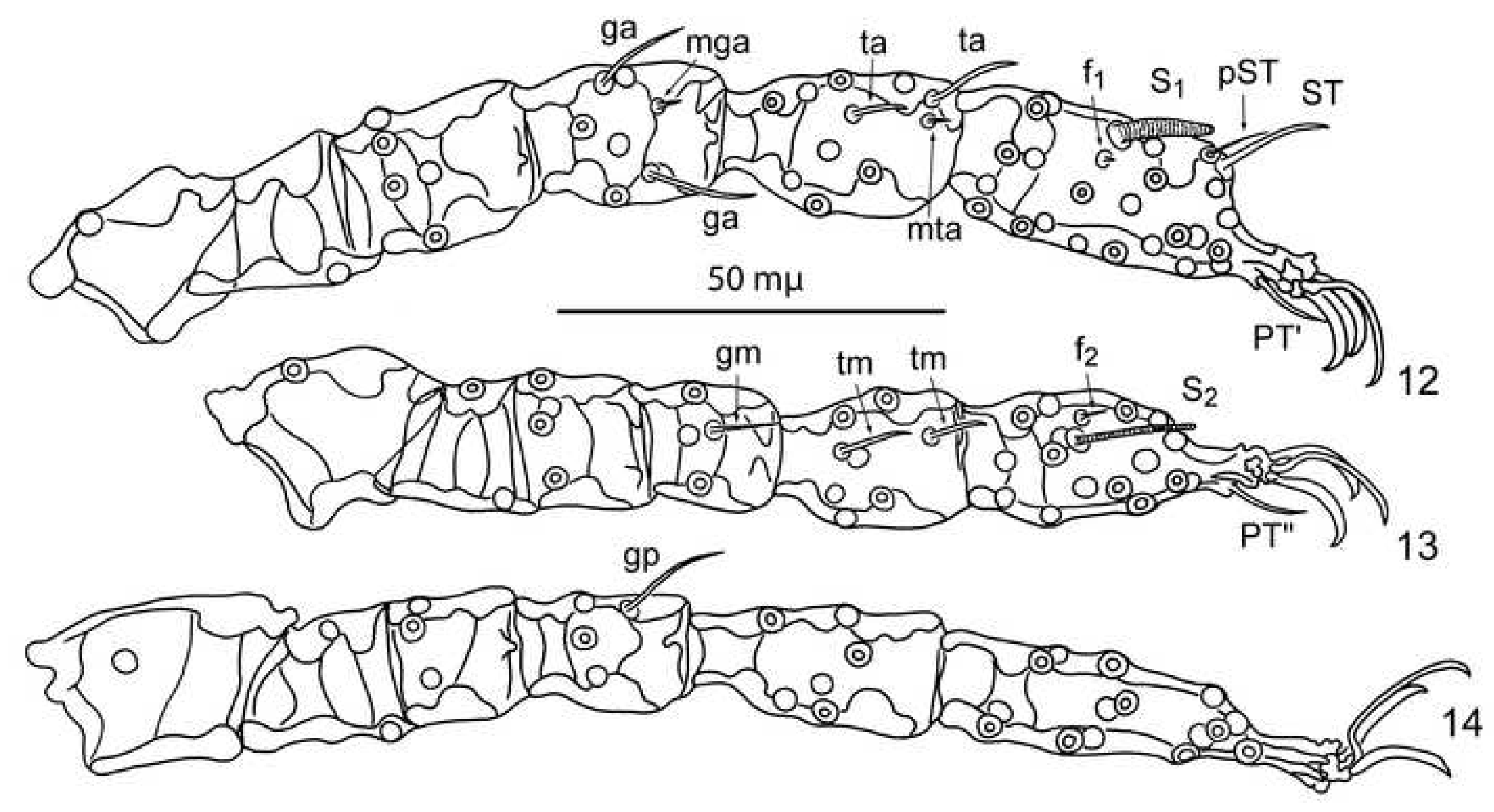



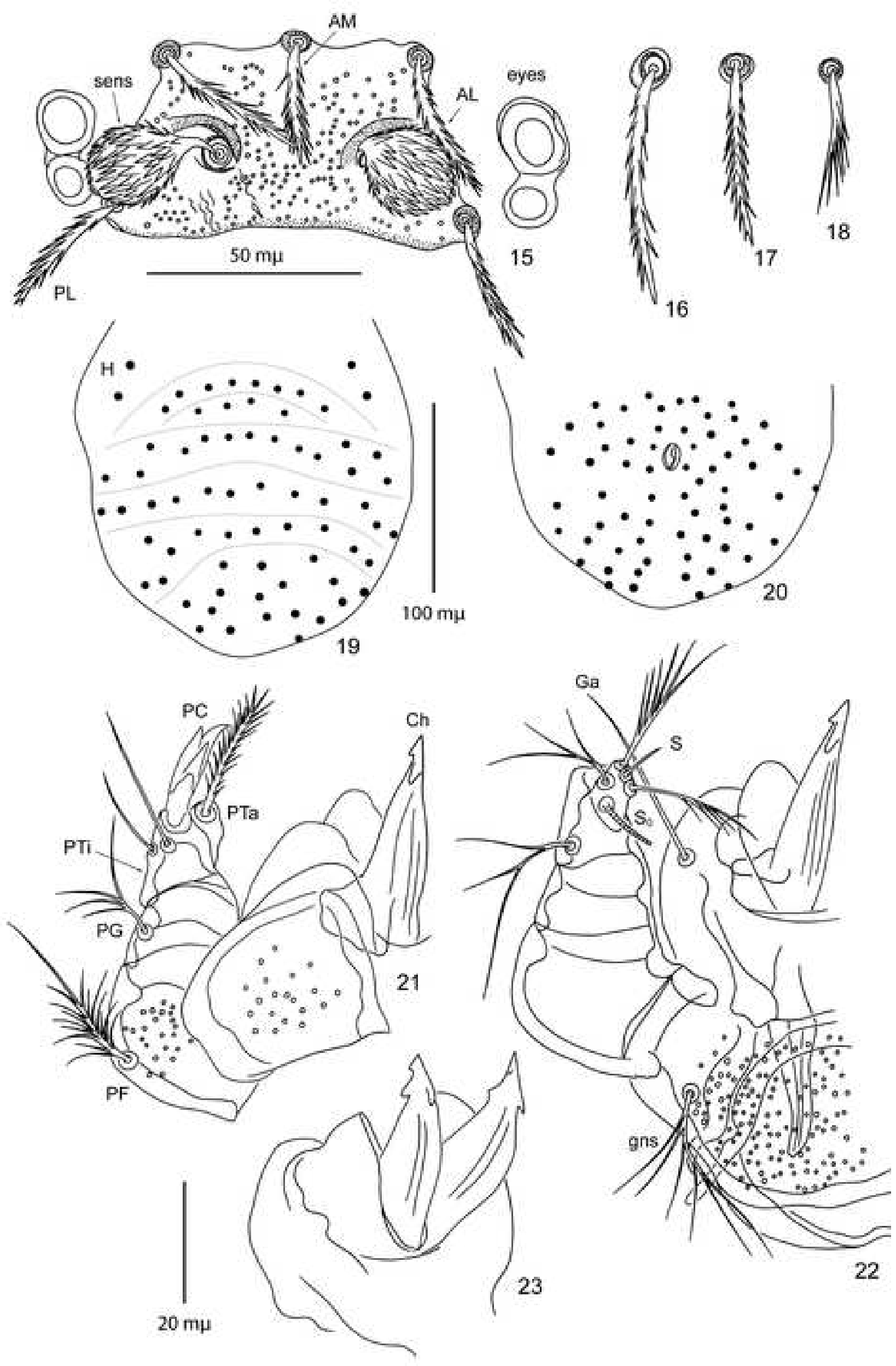
Click here to access/download;Colour figure;Figs24-26.tif $\underline{\underline{\Perp}}$
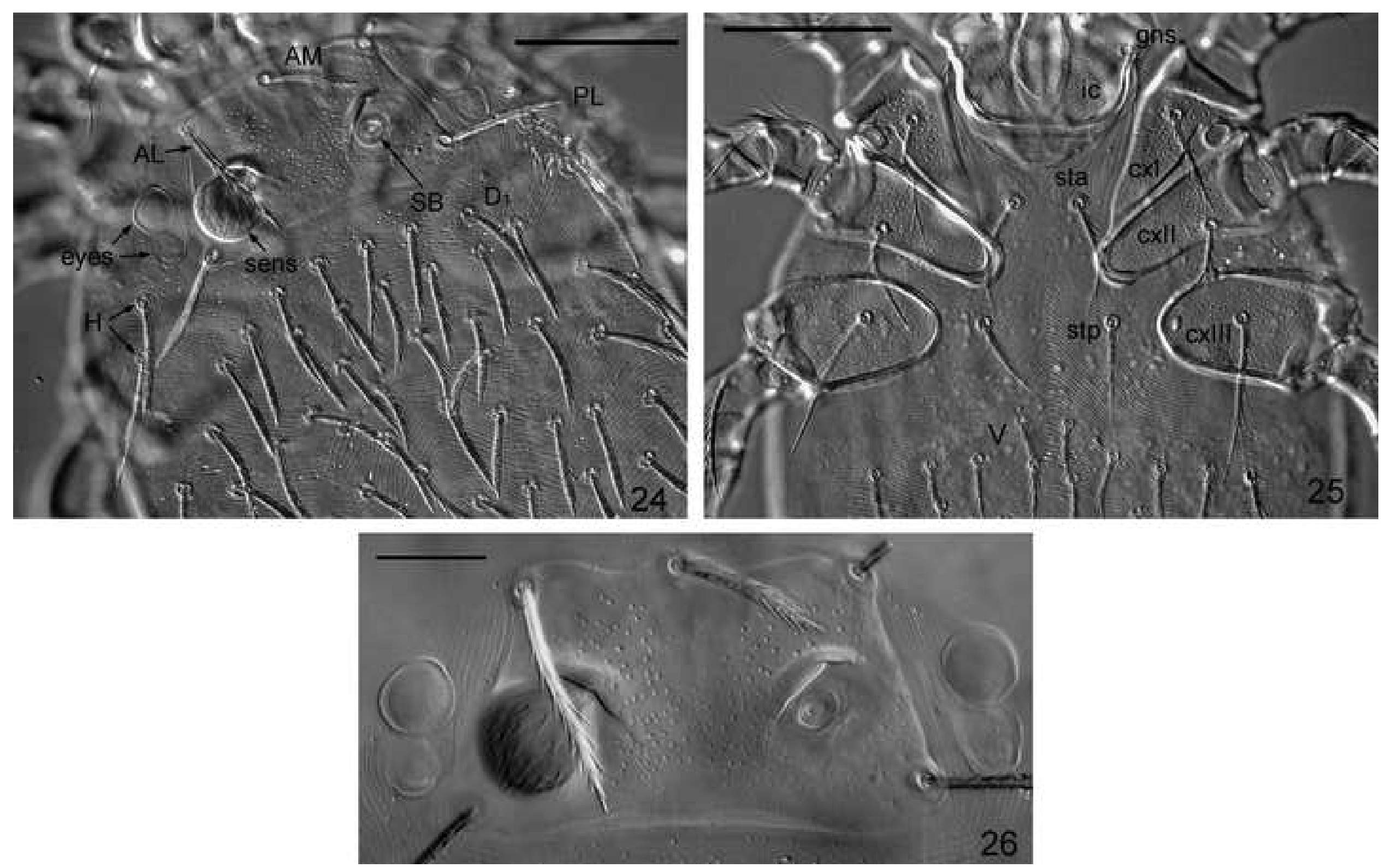


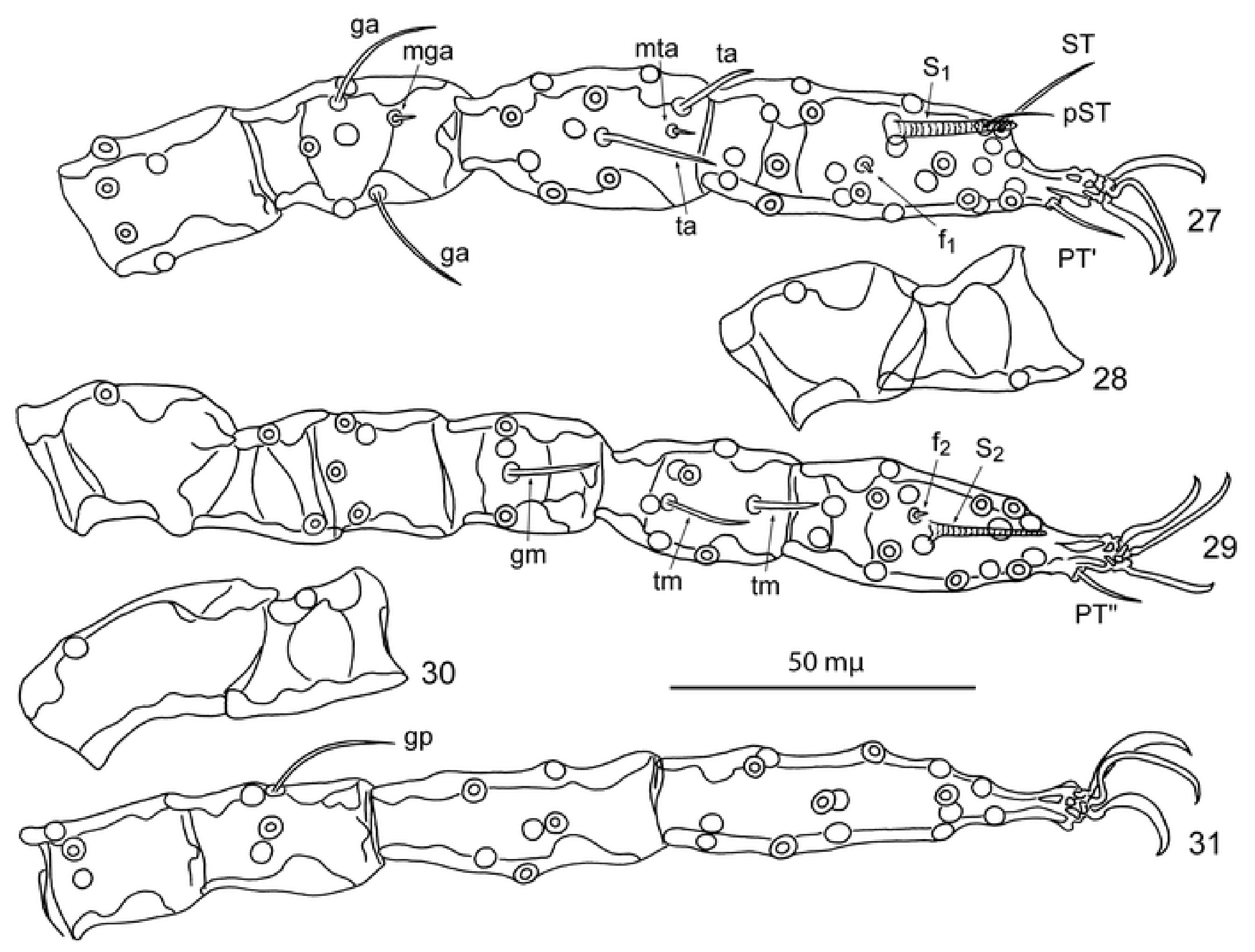


Cover letter

Dear Editor,

I enclose the final version of my accepted manuscript including its text corrected according to the editorial remarks and figures of high resolution (line figures at $1200 \mathrm{dpi}$ and plates of photographs at 600 dpi).

Sincerely Yours,

Alexandr Stekolnikov 